\title{
A NOÇÃO DE PESSOA E A CONSTRUÇÃO DE CORPOS KAINGÁNG NA SOCIEDADE CONTEMPORÂNEA ${ }^{1}$
}

\author{
PATRÍCIA CARVALHO ROSA ${ }^{2}$
}

UFRGS

\begin{abstract}
RESUMO: Este artigo aborda a noção de pessoa entre os Kaingang. Tal noção tange aspectos e instituições diretamente relacionados ao entendimento nativo acerca de corporalidade, sendo o nome e o corpo os seus princípios mais relevantes. Nesse sentido, a discussão abrange as noções êmicas que geram sentidos e significados às práticas sociais de construção do corpo e do sujeito social a partir dos relatos e experiência de campo com sujeitos Kaingang que residem na região metropolitana de Porto Alegre, durante o periodo de março a dezembro de 2007. Nesse contexto, a pessoa é entendida como um conjunto de conhecimentos, práticas e significados sociais que constituem uma trama de relações de sociabilidade naquilo que compõe sua cotidianeidade. Esse conjunto de fatores expõe a complementaridade entre os papéis de gênero e as características especificas do dualismo Kaingang.
\end{abstract}

PALAVRAS-CHAVE: cosmologia; dualismo; corporalidade; gênero; Kaingang.

ABSTRACT: This paper aims to discuss some aspects related to the concept of person and embodiement among the Kaingang. Througout an analysis of this terms used as a form of native self-designation, the article discuss how the construction of the body and person are articulated with gender dichotomies, social espaces and social practices of construction of the body and the social drawing on fieldwork data collected among the Kaingang who live in the metropolitan region of Porto Alegre, during the period from March to December 2007. In this context, the person is perceived as a body of knowledge, practices and social meanings that is constituted by a complex of social relations daily built.This set of factors explains the complementarity between the roles of gender and the specific characteristics of dualism Kaingang.

KEYWORDS: cosmology, dualism, corporality, gender, Kaingang.

\footnotetext{
${ }^{1}$ Este artigo foi organizado a partir do capítulo de mesmo nome resultado da monografia produzida para o trabalho de conclusão do curso de Ciências Sociais (2008). Agradeço a colaboração do Prof ${ }^{\circ}$. Sérgio Baptista da Silva, Guilherme Orlandini Heurich e ao parecerista anônimo pela revisão e observações que foram muito pertinentes.

2 Graduanda em Ciências Sociais na Universidade Federal do Rio Grande do Sul. E-mail: pati_cr@hotmail.com .
}

Espaço Ameríndio, Porto Alegre, v. 2, n. 1, p. 15-43, jan./jun. 2008. 
De maneira geral, as etnografias produzidas até o momento sobre os Kaingang pouco privilegiaram o contexto das práticas sociais relacionadas às dicotomias de gênero. Tampouco, encontram-se materiais variados acerca de estudos sobre noção de pessoa, concepção e construção de corpos Kaingang que tangem o cotidiano desses sujeitos (SILVA, 2005). Muito se conhece sobre os processos de nominação, organização política e social (VEIGA, 1994; FERNANDES, 2003), sobre o xamanismo, significações sobre morte e desconstrução do corpo (ROSA, 2005; CRÉPEAU, 1997 e 2006). O tema desse trabalho procura abarcar justamente algumas lacunas encontradas nas etnografias produzidas sobre os Kaingang, visando apreender, a partir do ponto de vista nativo, os sentidos e significados relacionados a gênero, práticas e conhecimentos no que tange às reflexões sobre a noção de pessoa e construção de corpos nessa sociedade. O foco analítico concentra-se no cotidiano experimentado e vivenciado junto às mulheres Kaingang em seus núcleos familiares ${ }^{3}$. O cerne da discussão foi elaborado inicialmente a partir das reflexões sobre o papel da mulher Kaingang na construção de corpos sociais em uma sociedade patrilinear. O questionamento norteador parte do entendimento de que as práticas sociais expressam-se tal qual o modelo de organização dual desse grupo explicando o modo de ser e estar no mundo, estando subjacentes, aspectos mito-cosmológicos que entre os grupos Jê de modo geral e, para os Kaingang, revela uma importante concepção de complementaridade e oposição (CRÉPEAU, 2006). Nesta perspectiva, cabe ainda ressaltar que a perspectiva holística indicada por Crépeau (1997), na qual o dualismo Kaingang concebe contrastes em função dos contextos variados e modificáveis no plano da organização social que revela que as oposições de ordem ideológicas são constructos simples como uno/múltiplo, centro/periferia, masculino/feminino. Tais oposições são expressas também nas práticas sociais quando seu significado é comunicado a partir de seu uso. A partir disso, a discussão entre as dicotomias de gênero é um campo que demonstra atuação distinta entre homens e mulheres e as diferentes relações destes com o espaço social de sociabilidade marcado pela relação de contrariedade e

\footnotetext{
${ }^{3}$ Núcleos familiares são considerados nesse trabalho como casal, filhos solteiros e/ou casados que residem em uma mesma casa, conformando assim, uma família nuclear.
} 
PATRÍCIA CARVALHO ROSA - A noção de pessoa e a construção de corpos Kaingang ...

complementaridade entre as metades Kamé e Kairú (CRÉPEAU, 2005; ROSA, 2005; FERNANDES, ALMEIDA e SACCHI, 1999).

Diferentemente dos homens, a atuação das mulheres no campo das relações políticas Kaingang é percebida e analisada à luz das oposições conceituais e sociológicas que definem o modelo assimétrico (CRÉPEAU, 2006) de estabelecimento das relações sociais entre os sujeitos no contexto dos padrões de sociabilidade Jê. Tal modo de atuação feminina é observado no contexto dos núcleos domésticos, local constituído pela casa e pela extensão desse território (mato, o pátio e locais onde se reúnem por ocasião da venda de $\operatorname{artesanatos}^{4}$ ) que reúne mulheres geralmente ligadas por laços de afinidade e parentesco. Suas funções relacionam-se mais especialmente a produção do artesanato nos espaços domésticos e também no espaço de venda, onde ainda são responsáveis, em alguns casos, pela organização desse último local, no qual, na companhia de seus filhos solteiros e do companheiro, elas vendem e tomam conta das barracas. A relação de simetria esboçada aqui entre o espaço da casa, incluindo o local de venda como extensão dos termos da ideologia, ocorre devido ao fato de, no contexto etnografado, ambos refletirem uma discussão política relacionada à comercialização do artesanato, nas quais as mulheres também assumem papel relevante nas reivindicações.

A sociedade Kaingang, pertencente ao grupo lingüístico Macro Jê, apresenta uma organização social dual marcada pela existência de duas metades exogâmicas e patrilineares, que em uma relação assimétrica, são complementares e opostas (SILVA, 2001). No entanto, Crépeau (2006) ressalta que a relação harmônica entre tais metades pode parecer um acontecimento ilusório, na medida em que, nessas sociedades, o dualismo é marcado também pelas relações de poder, o que segundo os próprios Kaingang, implica conflitos, competições e hierarquia. Nesse modelo assimétrico, as metades duais conhecidas como Kamé e Kairús são representações cosmológicas relacionadas ao

\footnotetext{
${ }^{4}$ O local é o Brique da Redenção, localizado no bairro Bom Fim em Porto Alegre, onde aos domingos é reservado aos Kaingang um espaço para a comercialização de seu artesanato. Tal espaço constitui-se local não somente de comercialização, mas de sociabilidade entre as famílias Kaingang e espaço de articulação política. Conforme Freitas (2005).

5 Tais metades apresentam-se visualmente por marcas de riscos compridos e círculos ou formas arredondadas, respectivamente (SILVA, 2001). As metades Kamé e Kairú reúnem um conjunto de predicados que estão presentes em outros grupos Jê. Os Xerente apresentam dois irmãos míticos
}

Espaço Ameríndio, Porto Alegre, v. 2, n. 1, p. 15-43, jan./jun. 2008. 
PATRÍCIA CARVALHO ROSA - A noção de pessoa e a construção de corpos Kaingang ...

mito de origem do grupo. O Kamé é o primeiro, o mais forte, estando associado ao leste, ao sol, ao seco, ao masculino, ao poder político e ao xamanismo. A metade oposta Kairú é tida como mais fraca, relacionada ao oeste, à lua, ao feminino, a água e à organização de ritos funerários (CRÉPEAU, 2006). Os Kaingang têm representado nos irmãos míticos a origem das metades e seus atributos particulares. Segundo Nimuendajú (1993), o mito possibilita uma melhor compreensão acerca do modo como é estabelecida a organização social Kaingang e suas instituições constituídas. A partir disso, a classificação êmica abrange todos os seres, objetos e fenômenos naturais. Silva (2001) nota que além da diferença ser pensada através do pertencimento a uma das metades, os Kaingang entendem que o dualismo é apreendido como uma complementaridade, onde a existência de uma contraposição é essencial. A oposição hierárquica entre o Kamé e Kairú ressalta a perspectiva holística onde o primeiro é englobante do segundo e, nesta relação idealmente formulada, os Kaingang, de modo geral, apresentam as disposições duais nas práticas cotidianas.

Considerando esses aspetos sobre a organização social e cosmologia o presente artigo trata da concepção de pessoa Kaingang, seus processos cotidianos de formação e construção de corpos. Nesse sentido, duas dimensões centrais enfocam a corporalidade: nome e corpo. Esses dois conjuntos de saberes envolvem conhecimentos específicos que através de ações cotidianas revelam os significados que dão sentido ao próprio conceito de pessoa; o que difere na prática, um corpo Kaingang de outros corpos.

O primeiro deriva do domínio da natureza e refere-se à metade que o sujeito pertence, seguindo a regra da patrilinearidade. A instituição da nominação Kaingang é, por outro lado, um modo de perceber como o dualismo está presente nas relações cotidianas do grupo e que, sobretudo, marca e identifica o sujeito, atribuindo-lhe substâncias que constituem sua identidade e corpo (VEIGA, 1994).

O segundo, referente especificamente à corporalidade, provém das práticas sociais específicas que visam possibilitar ao sujeito a incorporação e manutenção de propriedades e substâncias que formam seu caráter e corporalidade (SEEGER, DA MATTA e VIVEIROS DE CASTRO,

relacionado à constituição das metades Sdakrã e Siptato (VEIGA, 1994).

Espaço Ameríndio, Porto Alegre, v. 2, n. 1, p. 15-43, jan./jun. 2008. 
PATRÍCIA CARVALHO ROSA - A noção de pessoa e a construção de corpos Kaingang ...

1987; SEEGER, 1980). Tais práticas envolvem atividades que são desenvolvidas pela mãe e outras mulheres que constituem o espaço doméstico e que pertencem à metade oposta do filho(a) e, outras que são realizadas pelo pai e outros homens que formam o espaço público de convivências. A existência do vínculo entre $o$ nome e suas propriedades particulares e o corpo conformam o conceito de pessoa Kaingang.

\section{A existência da pessoa: a construção e desconstrução de corpos}

A pessoa Kaingang é entendida a partir de uma relação assimétrica entre as metades clânicas Kamé e Kairú, onde a noção e constituição do sujeito social se dá através do outro (VEIGA, 1994). Desse modo, cada Kaingang teria sua identidade social elaborada através das características e atributos idealmente referenciados no mito de origem e constituída através da diferença ${ }^{6}$. Nessa perspectiva, a categoria de pessoa é tida como fruto da relação entre a natureza e a sociedade. Gãn Rhe comenta explicando-me, que o corpo para os Kaingang é formado de um modo distinto daquele dos brancos. 0 corpo, segundo ela, é uma extensão do domínio cosmológico da natureza ${ }^{7}$ :

O corpo da gente é parecido com o corpo dos animais. Os bichinhos vivem bem e conseguem crescer, criar os filhinhos só quando estão perto da natureza. Onde tem os remédios e comidas deles. Com o Kaingang é assim, viu. Trocamos sempre com a natureza. Antes mesmo de nascer a criança já tá em contato com o mato. Com os banhos de chá e remédios que a mãe toma. O nome vem das coisas do mato. E depois cresce e continua com a natureza. Agora tá mais difícil por causa do desmatamento, da ocupação das Terras Indígena, as

\footnotetext{
${ }^{6}$ Viveiros de Castro (2002) diz: "Não há relação sem diferenciação. O que em termos sociopráticos, é dizer que os parceiros de qualquer relação estão relacionados porque são diferentes entre si, e não apesar de o serem. Eles se relacionam através de sua diferença, e se tornam diferentes pela sua relação" (VIVEIROS DE CASTRO, 2002, p. 422). Desde esse ponto de vista, relaciono essa perspectiva com o universo Kaingang, pois, tal noção esclarece que as relações de afinidades construídas através e nas práticas de sociabilidade revelam, nesse sentido, aquilo que para os Kaingang é um aspecto importante no seu modo particular de organização social: o dualismo e assimetria.

${ }^{7}$ Domínio este que é definido como médio ou domínio da Terra constituído pelos espaços da casa, espaço limpo e a floresta virgem. Esta última é considerada como um espaço Kamé, pois engloba no nível cosmológico, os outros dois domínios - do alto e o do subterrâneo. Ver melhor em Rosa (2005).
}

Espaço Ameríndio, Porto Alegre, v. 2, n. 1, p. 15-43, jan./jun. 2008. 
PATRÍCIA CARVALHO ROSA - A noção de pessoa e a construção de corpos Kaingang ...

plantação de soja e trigo conseguirmos manter isso tudo, acaba que não vivemos mais tão com a natureza que a relação entre ele e o Kaingang vai ficando fraco, sabe. Mas depois quando o espírito fica fraco, adoentado e o Kujà ${ }^{8}$ não consegue resolver, a pessoa acaba. O corpo fica sem o Kuprig ${ }^{9}$. Vai cada um pra um lugar. O espírito pra junto dos outros lá no Numbê ${ }^{10} \mathrm{e}$ o corpo fica aí na terra (GÃN RHE, junho de 2007).

A pessoa Kaingang, segundo relatos de alguns interlocutores, é constituída pelo corpo. Mas pelo corpo em relação ao seu espírito. Ambos, sofrem cotidianamente, intervenções que envolvem a alimentação consumida no contexto doméstico, atividades relacionadas as tarefas da casa, de cuidados com a roça, conhecimentos sobre as relações políticas e também práticas e rituais envolvendo a figura do kujà. Tais práticas são contínuas, por vezes quase invisíveis, marcadas por atividades rituais, como banhos periódicos com remédio do mato e outras atividades públicas como caminhadas no mato para conhecer e aprender sobre as ervas, os animais e outros temas relacionados a relação do corpo com a natureza. No entanto, sempre coletivas, envolvendo pelo menos dois sujeitos, seja a mãe (manh) e as filhas (kósin), sogro (kakrã) e genro (jamré), avós e netos, aluno e professor. No referencial teórico Jê tal aspecto apresenta-se como reflexo da lógica da complementaridade entre os Kaingang, onde, idealmente, as atividades são realizadas e compartilhadas aos pares. As práticas relacionadas à formação do corpo e do espírito não são desvinculadas, relacionando-se de distintas maneiras. Pelo que pude apreender em campo, corpo e espírito, embora tenham origens distintas, constituem um mesmo ser Kaingang ${ }^{1}$.

\footnotetext{
${ }^{8}$ Kujà é o termo no idioma Kaingang que designa xamã.

${ }^{9}$ No entendimento Kaingang há pelos menos dois distintos modos para a compreensão da palavra espírito. Iamgré refere-se aos espíritos guias, como traduzido pelos informantes, que auxiliam os xamãs em suas práticas de cura. E kuprig designa a outra parte, além do corpo que constituí pessoa Kaingang e, que, independente de sua função ou metade, todos possuem.

${ }^{10}$ Domínio cosmológico do território Kaingang no qual se encontram os espíritos dos mortos. Ver Rosa (2005).

${ }^{11}$ Ao mencionar que as práticas de formação do corpo Kaingang são contínuas procuro esclarecer que a constituição da pessoa inicia no momento da relação sexual entre os genitores, seguindo pelos meses de gestação, o nascimento, o processo de nominação, as constantes práticas cotidianas e rituais durante a infância, juventude e vida adulta. A morte corresponde ao momento em que o corpo e o espírito separamse definitivamente. Ao corpo, os cuidados aplicados são distintos daqueles que recebe o espírito, sendo tais práticas fundamentais nesse momento de mudança. Esse longo período desde a fecundação até a morte considero como sendo a existência da pessoa Kaingang. No momento da morte se desfaz, portanto,
}

Espaço Ameríndio, Porto Alegre, v. 2, n. 1, p. 15-43, jan./jun. 2008. 
PATRÍCIA CARVALHO ROSA - A noção de pessoa e a construção de corpos Kaingang ...

Reféi, ao perguntar durante uma conversa informal como a "pessoa branca" era constituída, eu e mais dois companheiros de pesquisa não soubemos responder imediatamente a sua questão. Falamos que cada pessoa era formada de um modo, dependendo ainda de suas crenças e experiências. O professor Kaingang responde:

Pois bem, a pessoa Kaingang é diferente. Do mesmo modo como o branco acredita em suas religiões e tudo isso, o índio também tem suas crenças. Mas a pessoa não tem muito a ver com essas coisas. Todo índio Kaingang é feito da mesma coisa. Mesmo esses que não vivem na cultura; o corpo deles é parecido com o meu. A diferença é que eu cuido dele como aprendi com minha mãe e com os mais velhos. Daí, sei ensinar isso pros meus filhos também. Tem uma parte que é o kuprig. É dito assim, como o espírito em português. Ele fica junto com o corpo da pessoa; com a parte essa que a gente enxerga. Mas ele pode sair. Quando sai o corpo fica enfraquecido, por isso ficamos doente. Mesmo que o corpo seja saudável, tem que cuidar também desse Kuprig pra que ele fique sempre fortalecido e não seja raptado pelos outros tipos de kuprig. Tem aqueles kuprig korég ${ }^{12}$ que vivem rodeando aqui o mundo dos vivos; dizem que eles têm saudades dos parentes. Por isso raptam os kuprig e levam lá pro mundo deles. Por isso tem que cuidar dele, com banhos e a fumaça. Mas o kujà consegue trazer ele de volta. Se não consegue a pessoa morre. Aí volta tudo de novo. O corpo fica só corpo e enterramos na terra onde a pessoa nasceu ou teve seu umbigo enterrado. E o kuprig dela vai embora junto com o nome. Esse nome pode ser depois de outra pessoa quando nascer. Mas o espírito não. Ele fica lá na aldeia dele juntos com os outros kuprig. Entenderam, é assim, tem duas partes que fazem a pessoa ser Kaingang. Nem todos acreditam, fazer 0 que? (REFÉI, abril de 2007).

Os relatos de Gãn Rhe e Reféi convergem para uma mesma idéia sobre a noção dual de pessoa Kaingang. Expressam em suas explicações a existência de uma complementaridade essencial entre a parte por eles

o processo de existência da pessoa uma vez que os dois fatores que a constituem são, propositalmente, separados.

${ }^{12}$ Kuprig korég é uma categoria de espírito considerada negativa e, entre muitos Kaingang, é temida por sua capacidade de raptar o kuprig das pessoas o conduzindo ao numbê, local de onde somente é resgatado com a ajuda do kujà. Tal evento torna o corpo fraco e a pessoa fica doente e, se o kuprig não é resgatado a tempo a pessoa corre o risco de falecer.

Espaço Ameríndio, Porto Alegre, v. 2, n. 1, p. 15-43, jan./jun. 2008. 
chamados de hã que constitui o corpo visível e uma segunda parte kuprig - não perceptível fisicamente, mas que de algum modo, está em comunicação com os outros níveis ou domínios do território Kaingang tal como sugere Rosa (2005). Esse vínculo entre o hã e o kuprig é a relação que constitui aquilo que entre os Kaingang é denominado de pessoa. Essa categoria nativa é ao mesmo tempo constituinte de um sujeito social, onde o nome, especificamente, expressa as possíveis características da personalidade, uma vez que está relacionado ao mito dos irmãos gêmeos Kamé e Kairú e seus respectivos atributos. O nome se remete ao sistema de classificação da natureza, sendo ele mesmo o elo de estabelecimento da relação mencionada entre ela e a sociedade Kaingang. E por outro lado, a parte física proporciona compreender as relações de substâncias e trocas que o constitui durante o desenvolver de sua vida. Sugiro, a partir dessas informações que o kuprig seria a parte dada após o nascimento, recebida através do nome e formada das relações entre os sujeitos, o cosmos e, especificamente com o domínio da natureza. Enquanto que o corpo, de modo distinto, é construído desde o instante da cópula e segue sua formação constantemente no cotidiano de cada pessoa Kaingang.

\section{Hã e Kuprig: entendendo a categoria de pessoa e suas dimensões}

A palavra inh em Kaingang designa "eu". Refere-se ao sujeito que realiza algo, uma ação, que está no mundo. Nessa perspectiva, esse inh, segundo os informantes, refere-se à pessoa Kaingang, constituída pelo corpo físico e pelo espírito.

Quando eu te digo que eu sou uma pessoa Kaingang eu te digo essas palavras: inh ou isy ou ainda hã. Essas palavras querem dizer que eu faço algo, que sou capaz de fazer as coisas, que tem relação a mim (GÃN RHE, dezembro 2007).

Ainda segundo Gãn Rhe, ser um Kaingang é estar no mundo, agindo e relacionando-se com a natureza.

Não tem como eu ser uma Kaingang se eu não estiver perto do mato, de lá é que tiramos os chás que 
PATRÍCIA CARVALHO ROSA - A noção de pessoa e a construção de corpos Kaingang ...

ajudam o corpo a ficar forte, de lá é que vem os remédios pra tratar dos espíritos, sou eu que junto com a natureza e as outras pessoas, que nem minha vó, meus filhos, o marido, as primas e as comadres que fizemos o hã e o kuprig ficarem bem e juntos até quando der, depois é outra coisa que acontece (GÃN RHE, 2007).

A vida humana poder-se-ia dizer assim, estaria ligada a categoria de $I n h$, indicando assim, o estado do sujeito que age, vive e interage no mundo, ou, nos mundos. Sujeito que interage constantemente com o domínio da natureza do qual em uma relação recíproca, envolvendo saberes, deveres e trocas, compartilha elementos e substâncias - água, vento, alimentos etc. - que incorporam e formam o corpo e mantêm o kuprig $^{3}$. A categoria de pessoa para os Kaingang é aqui pensada a luz do modelo proposto por Viveiros de Castro (2002) onde a divisão entre o corpo e alma manifesta uma polaridade que segundo o autor traduz o cerne da questão sobre a concepção de tal categoria para os grupos ameríndios. Assim, a noção de pessoa Kaingang é o conjunto dos elementos práticos e simbólicos que envolvem a construção do corpo e a nominação. O nome, relacionado ao espírito, indica o caráter e atualiza as relações de consangüinidade, enquanto a construção do corpo, expressa em suas práticas, as relações também de afinidade. Seria o nome, assim, o elo que materializa a relação entre o socius e o cosmos.

Gãn Rhe menciona em seu relato acima que a presença dos afins e parentes consangüíneos faz parte da construção do corpo e do processo de constituição de identidade, na medida em que o sujeito percebe-se a partir do outro, da oposição Kamé/Kairú. Desse modo, ao observar o universo feminino e as atividades relacionadas à corporalidade percebese que as mulheres Kaingang relacionam-se compartilhando saberes, objetos, alimentos, experiências que as tornam próximas $^{14}$. Sociabilidade entre elas é explícita. Em outras palavras, nas práticas que

\footnotetext{
${ }^{13}$ Segundo informações de Rosa (2005) e Almeida (2004) o espírito dos vivos são seres invisíveis e imperceptíveis aos olhos dos Kaingang, com exceção dos Kujà, única pessoa capaz de resgatá-lo do mundo dos venh-kuprig-korég (espíritos dos mortos considerados ruins e que raptam os Kuprig dos vivos) onde fica confinado. Há ainda outra subdivisão dessa categoria denominada como venh-kuprig-há considerada como espíritos bons e protetores do numbé (Rosa, 2005, p. 168-171).

${ }^{14} \mathrm{O}$ conceito de afinidade é utilizado com o intuito de demonstrar que o fato de haver compartilhamento entre o grupo de mulheres torna possíveis as relações de parentesco entre elas.
} 
PATRÍCIA CARVALHO ROSA - A noção de pessoa e a construção de corpos Kaingang ...

constituem o seu universo específico e coletivo. Assim, o corpo, na perspectiva da corporalidade, segundo Seeger, Da Matta, e Viveiros de Castro (1987) opera como idioma simbólico que possibilita a definição e construção êmica de pessoa pela sociedade.

Mesmo antes de seu nascimento o sujeito Kaingang tem seu corpo em formação com práticas e ações que mais adiante exponho. Ao nascer, esse sujeito que até esse momento apenas tem um corpo, recebe através da nominação o segundo caráter fundamental na constituição da noção de pessoa: o nome. Ao recebê-lo de acordo com a norma da patrilinearidade, relacionada ao processo de constituição de parentesco Jê, o sujeito adquire os atributos da metade do pai. Sendo Kairú ou Kamé, o sujeito passa a ser referido, idealmente, pelas características da metade a qual pertence. Tal nome está ainda relacionado ao seu papel social na sociedade.

O hã, desde cedo, é formado através de substâncias de saberes que envolvem alimentação, sendo o leite e a água, por exemplo, elementos importantes na formação do corpo. O leite fortalece a criança e é um meio de trocas de substâncias que ligam mãe e filho e garantem um vínculo que apenas as mulheres mantêm por tempo mais longo com os filhos, diferentemente dos pais que mantêm o vínculo através das atividades realizadas na mata e no campo e menos no espaço doméstico da casa. A água através de banhos e/ou ingestão de chás preparados pelas mães e avós e também pelo kujà trata e previne doenças, bem como fortalece os kuprig. Esse elemento tem presença constante no cotidiano das mulheres na prática de atividades domésticas - preparo de alimentos, cuidados com a roupa - e as crianças sempre que possível, estão brincando próximo a um local onde tenha água (goj jonh'). A fumaça do fogo, outro elemento importante, protege a casa e o espaço social onde os sujeitos interagem e constroem a trama de relações sociais. Nesta fumaça está presente o cheiro que afasta os ventos que sopram vindos do numbê. A escolha da madeira com a qual se faz o fogo é uma preocupação entre os mais velhos que conhecem quais árvores exalam os cheiros que incidem sob os espíritos ${ }^{15}$. A partir dessa classificação dual dos elementos da natureza sabe-se, portanto,

\footnotetext{
${ }^{15} \mathrm{O}$ cedro e o pinheiro são árvores cuja madeira é ideal para que os homens produzam um bom fogo. A primeira é considerada Kairú; a segunda, Kamé. O eucalipto é considerado uma madeira de más propriedades segundo relato de Renrã em outubro de 2007.
}

Espaço Ameríndio, Porto Alegre, v. 2, n. 1, p. 15-43, jan./jun. 2008. 
no cotidiano como cada núcleo doméstico ou grupos de afinidade constituem essa prática de proteção do espaço e do corpo concomitantemente. A fumaça é mantida quase que diariamente próximo a casa e o pátio, local nos quais as crianças brincam e as mulheres produzem a cultura material. $O$ fogo é também um agrupador. Em seu entorno, se reúnem os grupos familiares para ter longas prosas. Geralmente ao cair da noite, os núcleos domésticos se reúnem para compartilhar as refeições e finalizar o dia, descansando o corpo.

O kuprig, a segunda categoria nativa formadora da pessoa Kaingang agrega-se, após o nascimento, ao hã. O evento que marca essa justaposição é a nominação da criança que ao receber o nome está incorporando ao mesmo tempo alguns atributos da metade clânica de seu pai e que será respectivamente a sua. Entretanto, diferentemente do corpo, por exemplo, o kuprig não pertence a nenhuma divisão clânica e tampouco designa características físicas ou sociais ao sujeito que tem o seu corpo como receptor. A fala de Gãn Rhe é esclarecedora nesse sentido,

Quando nasce, toda criança recebe pelo menos um nome e esse nome diz de quem ela é filha. Aí depois de receber esse nome e tomar um banho com as ervas certas que o kujà conhece a pessoa tá completamente formada. Lembra quando morreu a netinha da irmã Kengrimu? Pois é, ela nem chegou a receber nome, então era mesmo só o corpo. Por isso também era importante enterrar o corpo lá na aldeia, sabe. Por que isso aí diz que lá é terra Kaingang verdadeira, pois já tem um corpo lá. Não sei se colocaram também o cordão umbilical dela. Isso também é um jeito Kaingang de deixar o corpo perto da terra. Legitima, né? Como dizem. Eu tenho os umbigos dos meus guris mais velhos enterrados lá no Paraná, onde eles nasceram. O da Kapri tá lá na Borboleta e depois eu tenho que colocar os dos outros menores lá também, porque quero que aquela terra seja deles também. A gente diz assim: Hã pra qualquer corpo e quando a pessoa é Kamé aí se diz iongé e se a pessoa é Kairú aí diz Kanhé ré ${ }^{16}$. Assim, porque o corpo de cada um é diferente, né? Mas o kuprig não sabe disso. Ele não tem metade certa (GÃN RHE, janeiro de 2008).

\footnotetext{
${ }^{16}$ A grafia correta de tais termos não é de conhecimento de Gãn Rhe e das outras informantes, sendo escrito aqui do modo como se fala, buscando traduzir o mais fiel possível a sonoridade.
}

Espaço Ameríndio, Porto Alegre, v. 2, n. 1, p. 15-43, jan./jun. 2008. 
A partir desse relato, poderíamos pensar que a construção dos corpos Kaingang, é em si mesmo, práticas que expressam no e través do corpo, os sentidos e representações duais e de complementaridade Jê.

\section{Jiji: onomástica e dualismo}

Veiga (1994) sugere que o $\mathrm{Jiji}^{17}$ deve corresponder ao acervo de nomes que determinada metade possui. Esse nome, escolhido pelo kujà, quase sempre é um nome relacionado a elementos do mundo natural como pedras, madeira, pássaros etc. A pessoa que recebe o nome de uma pedra, por exemplo, incorpora os atributos e substâncias desse elemento, tornando-se nesse caso, uma pessoa forte e resistente a doenças. Entre os meus interlocutores, há Jagtyg. Seu nome indígena significa pedra cristal. Elemento que segundo ele "é muito resistente, pedra forte que se encontra no mato". Ele, um kujà há pouco tempo em atuação, conta que

o nome deve ser pensado de acordo com a metade que a criança tem; se ela é filha de um Kamé, o nome tem que informar isso, né? Que nem nos meus filhos. Eles têm nomes Kamé. Como eu sou kujà o nome tem que ser de acordo daí, vi? Uma pedra forte, daí eu sou preparado para não pegar doença fácil assim, duro, que nem a pedra (JAGTYG, agosto de 2007).

O nome Kaingang é uma identidade social e também cerimonial. $\mathrm{O}$ Jiji define a pessoa enquanto sujeito social e também suas características substanciais - que define quais as funções e papéis que poderá desempenhar como é o caso dos péin, por exemplo, que atuam em momentos rituais funerários. "Com o Jiji, o indivíduo recebe os papéis sociais e/ou cerimoniais correspondente ao nome. Segundo os Kaingang, pelo nome da pessoa se pode saber se ela é Kamé ou Kairú" (VEIGA, 1994, p. 128). Sobre esse aspecto Jagtyg, comentara que:

Têm alguns jeitos de saber se um Kaingang que a gente não conhece é Kamé ou Kairú. Um é olhar pro jeito que ele tem o corpo. Pelas unhas, se é mais redonda é Kairú,

\footnotetext{
${ }^{17}$ Nome em Kaingang.
} 
PATRÍCIA CARVALHO ROSA - A noção de pessoa e a construção de corpos Kaingang ...

se for mais fininha e comprida é Kamé, daí. Se o corpo for longo é Kamé. Se a pessoa diz o nome também, viu. Aí se sabe. Porque o nome dela deve dizer se ele é Kamé ou Kairú, aí também se sabe quem é o pai (JAGTYG, em agosto de 2006).

Conversando com algumas mulheres Kaingang, entre elas Kengrimu e sua mãe, Renrã, elas contam que independente do sexo os nomes dados às crianças ao nascerem são transmitidos respeitando a metade do pai. Relatam que em seu núcleo doméstico há uma criança que recebeu o nome Kaingang de Kusun rój ${ }^{18}$ (cor de rosa). Essa criança tem o pai pertencente à metade Kainú, sendo ela consequentemente, também uma Kairú. Explicam a origem do nome:

Kusún rói é cor de rosa no nosso idioma. É uma cor que é mais fraca. O vermelho é uma cor bem forte e é dos Kamé. O cor de rosa a gente tira de um cipó que é também da metade Kairú, porque ele é desses mais grosso assim, meio redondo, viu já? Mas esse cipó dá ao redor de uma árvore que é Kamé. Daí o nome do menino é um pouco da metade Kairú do pai dele e também da metade Kamé que é a mãe. Pode ter um nome só do pai, mas também pode ter dois pra dizer também da metade da mãe. Porque é que nem na natureza, né. Nada é assim feito sozinho tem que ser com um pouco de cada um. Que nem a onças de antigamente que os homens caçavam pra gente comer. Elas tinham as pintas e a cor da pele. As pinta diziam que eram Kairú e a cor da pele assim dizia que eram da outra também. Um pouco da mãe, né e um

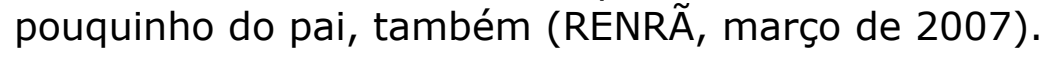

Assim, a discussão que proponho segue no sentido de apontar o princípio de reciprocidade e complementaridade Jê. Isto é, ao receber o nome que a identifica com uma metade específica, no caso a Kairú, mesma de seu pai, o cor de rosa, por ser entendido como uma possibilidade de, a partir da prática de nominação, estar também implícito nessa regra social que a criança receba alguma característica que a relacione com a mãe e sua respectiva metade. Sendo o nome um elemento fundamental na constituição da identidade Kaingang, o exemplo mencionado poderia estar revelando que ao nomear a criança como Kusun Rói tal evento não nega a participação feminina na

\footnotetext{
${ }^{18}$ Rój designa ainda algo ainda não maduro, claro, desbotado.
} 
PATRÍCIA CARVALHO ROSA - A noção de pessoa e a construção de corpos Kaingang ...

formação desse sujeito, trazendo, portanto, outra perspectiva para pensar o dualismo Jê. Nesse sentido, diferente daquelas informações conhecidas através da bibliografia sobre nominação (VEIGA ${ }^{19}$, 1994; SILVA, 2005), o que parece estar sendo revelado é que a complementaridade é uma característica constitutiva da pessoa Kaingang e que nessa importante instituição social percebe-se que "a filosofia de estabelecer relações idealmente harmoniosas entre os opostos é uma das expressões mais marcantes do pensamento Kaingang" (SILVA, 2005, p. 4).

Gãn Rhe relata como é que os nomes Kaingang têm referências a ambas as metades clânicas Kamé e Kairú.

A criança recebe dois nomes. Um que diz sobre a metade do pai e outro que diz sobre a metade da mãe. Esses nomes são escolhidos pelos avós ou pelos kujà. Eles sabem um monte de nomes em Kaingang que são para os meninos e para as meninas. Tem também os nomes de cada metade que tem que respeitar. Mas sempre o primeiro nome é o do pai, né? Aí, assim, as crianças recebem um pouco das qualidades do pai e da mãe também porque os dois formam a criança, né? (...) os nomes dos meus filhos são esses, vou te contar iniciando pelo mais velho. O Katu me que significa jabuticaba. Katu é fruto no idioma ${ }^{20}$ e me é uma fruta Kairú como eu. Depois tem o Karindé que é guabijú em português, aí vem a Kapri que é árvore branca. Árvore é ka e branco se diz kupri. Depois vem o Ken Che que é nó de pinho em Kaingang. O nenê que é Kenghen tartaruga que é Kairú e a outra parte do nome dele é de furão que é Kamé, aqueles bichinhos bem rápidos sabe (GÃN RHE, dezembro 2007).

Esse relato corrobora a perspectiva de que também no nome é possível perceber a participação das mulheres na constituição da pessoa, fato esse que responderia em algum grau a pergunta que gerou a investigação e o campo do qual esse texto é resultado, a saber, como opera a complementaridade dos papéis de gênero em relação à instituição da patrilinearidade Jê. "Os kujà sonham com os seus iangré

\footnotetext{
${ }^{19}$ Considero as possíveis distinções em relação as informações contidas na etnografia da autora, uma vez que há diferenças significativas referentes ao contexto temporal, geográfico, cultural, político e social dos informantes e universo de pesquisa. Desse modo, as informações de sua tese são aqui utilizadas como meio de comparação analítica dos dados de etnográficos.

${ }^{20}$ Segundo a informante, Katu seria a parte correspondente a metade Kamé.
} 
PATRÍCIA CARVALHO ROSA - A noção de pessoa e a construção de corpos Kaingang ...

que Ihes indicam os nomes adequados para a criança" diz Gãn Rhe. Esse nome, segundo ela, tem relação direta com o modo como tal criança vai agir sobre o mundo.

Vê o Kenghe ele é bem o que diz o nome dele. Ele tá sempre trepado em árvore, é rápido pra tudo e muito ágil, né, bem como o furão, aquele bichinho bem pequeno e habilidoso. Esse aí gosta também de uma água, nunca vi. Se deixar ele perto de uma piscina ele fica de molho que nem tartaruga (GÃN RHE, dezembro 2007).

Além disso, o nome recebido tem referências diretas às metades que formam o corpo e o espírito. Devido a isso, cada pessoa, idealmente, recebe dois nomes, embora não tenham sido todos os interlocutores que estiveram de acordo com essa informação. Veiga (1994) afirma haver três hipóteses para explicar a origem dos nomes Kaingang e como eles estariam operando no cotidiano das práticas sociais $^{21}$. Entre elas a autora destaca uma que faz referência a duas categorias de nomes: nomes bonito/bom (jiji hâ) e nomes feio/ruim (jiji korég). Desde o ponto de vista de Veiga (1994), ao analisar as categorias possíveis para nominação entre o grupo percebe-se que as categorias de bom e ruim são referências diretas a origem dos nomes que recebem os indivíduos. Temos assim nomes como Kaxin (rato do banhado) considerado um nome korég e ao mesmo tempo, nomes como Kanhérmby (rabo de macaco) identificado como nome bom. De acordo com o modo como esses elementos da natureza são percebidos e classificados pelos Kaingang, a utilização dos nomes corresponderá a uma função social para o sujeito que o recebe. Ou seja, o que está em jogo nesse processo de nominação é como ocorre por parte do indivíduo a incorporação de propriedades e substâncias que formam de seu caráter e corporalidade.

Os nomes são um modo de manter, em outras palavras, esse vínculo e, especialmente, marcar a complementaridade prescrita nos mitos, ritos e cotidiano Kaingang em relação ao dualismo. Diria, assim,

\footnotetext{
${ }^{21}$ No trabalho de Veiga (1994) é mencionado também que tais características encontram referências em trabalhos como de Baldus (apud VEIGA, 1994, p. 129) que atribui à categoria cerimonial dos péin como um nome ruim, devido ao papel desempenhado no ritual dos mortos. Wiesemann (apud VEIGA, 1994, p. 129) também ao analisar as categorias semânticas de "bom" e "ruim" encontrados na relação entre os nomes Kaingang afirmou que o nome é o elemento que confere o caráter ao indivíduo.
} 
PATRÍCIA CARVALHO ROSA - A noção de pessoa e a construção de corpos Kaingang ...

que essa norma social é menos rígida em relação ao que se conhecia acerca das questões de gênero e dualismo. No entanto, cabe observar que mesmo havendo complementaridade na instituição de nominação Kaingang em relação às metades clânicas, tal relação segue sendo assimétrica na medida em que há o englobamento dos aspectos maternos pelos paternos. Ou seja, ao receber nomes que tenham referência à metade da mãe, isso não significa que os aspectos paternos são ignorados.

E por fim, um último exemplo de outra criança que faz parte do mesmo núcleo doméstico do primeiro exemplo. Essa criança é chamada de Krig, estrela em Kaingang. Seu pai é filho do kujà pertence à metade Kamé. Assim, essa criança, é considerada da mesma forma como Kamé. Segundo um dos mitos de origem ${ }^{22}$ Kaingang as estrelas seriam filhas do sol e da lua. O primeiro considerado Kamé e o segundo Kairú. Numa possível analogia com o mito, que diz que os Kamé surgem primeiro e que a lua é em realidade um sol enfraquecido, o nome dessa criança remete à ordem da relação assimétrica e complementar que opera no sentido da constituição de noção de identidade. Assim, essas crianças Kaingang carregam em si características de ambas as metades e seus respectivos adjetivos.

Os nomes são, assim, "partes imperecíveis" da pessoa, mesmo depois de sua morte esse nome será atribuído a outra criança que venha a nascer, conseqüentemente, essa receberá os atributos que o nome designa (VEIGA, 1994, p. 128). O nome opera, portanto, como elo entre o presente, o passado e futuro. Desse modo, explica-se a importância de enterrar o morto em um local determinado. Ao morrer, o Kaingang deve ter o sepultamento de seu corpo no mesmo local onde fora enterrado seu cordão umbilical. Esse processo está diretamente relacionado a legitimidade da terra como um elemento fundamental para a formação e manutenção da pessoa Kaingang. Na terra é que encontram muitos dos componentes que formam o corpo - alimentos, por exemplo - e resulta daí a preocupação constante em preservá-la para garantir que o mundo natural não seja destruído. Como dito anteriormente, o nome que formará o espírito da pessoa Kaingang está na natureza - nomes de pedras, animais, vegetais, etc. - e nesse nome é

${ }^{22}$ Ver mito em Crépeau (1997, p. 176-177). 
PATRÍCIA CARVALHO ROSA - A noção de pessoa e a construção de corpos Kaingang ...

que encontramos as características que possibilitam o elo entre o mundo dos humanos e não humanos.

\section{Etnografando o universo feminino: conhecendo os processos da constituição da pessoa Kaingang}

O corpo é para os grupos indígenas, na perspectiva abordada por Seeger (1980), uma matriz de significados sociais e simbólicos e ao mesmo tempo objeto de significação social coletiva. O corpo não é tido por simples suporte de identidades e papéis sociais, mas sim, como instrumento, atividade, que articula significações sociais e cosmológicas.

Entre os Jê, o corpo parece estar seguindo a lógica dual de organização: por um lado a representação do interno - fluidos corporais - e por outro, aspectos externos - nominação, cerimônias - (VEIGA, 1994). Assim, o que se sugere é que a complementaridade entre o socius e os aspectos cosmológicos é que formaria um processo de construção de um corpo Kaingang e constitui a comunidade de substância Jê. No entanto, para não voltar as questões aqui refutadas de dicotomias corpo/alma, social/indivíduo é necessário ter esclarecido que, enquanto categoria nativa, o corpo não é uma totalidade (VIVEIROS DE CASTRO, 1979 e 2002). Nesse contexto, o uso do conceito de corporalidade adequa-se, na medida em que revela haver nessas sociedades uma dialética para a compreensão da constituição de um sujeito social. Essa se define por uma pluralidade de níveis e significados internamente estruturados. Ao mesmo tempo em que se tem uma matriz de cunho individual (sêmen, sangue, espaço na aldeia (casa)) tem-se o coletivo ou social (alma, nome, papel). Isso revela que tal oposição dual pode ser revertida, justamente, por ser o corpo o locus privilegiado tido como cenário para essa possível convergência. É no corpo que se constitui a arena para o processo de devir e de uma definição dialética de continuidade. Nessa mesma perspectiva, Terence Turner (1995) afirma, a partir de seus estudos com os Kayapó, que o corpo deve ser entendido enquanto um conjunto de sentidos que congrega os aspectos sociais, biológicos e culturais, constituindo uma 
identidade social no qual ele é o produto e produtor da estrutura e da cosmologia.

A partir desse referencial é que apresento o próximo tópico deste artigo o qual considero mais relevante em termos de colaborações para seguirmos pensando as próximas etnografias com grupos Kaingang. Assim, a análise segue no sentido de expor algumas práticas relacionadas ao processo de formação e constituição de corpos Kaingang, apresentando algumas informações acerca da gravidez, gestação, nascimento e outros momentos que envolvem tal temática.

\section{Ideologia da concepção: o surgimento do corpo e a formação da pessoa}

Gãn Rhe conta que sendo o corpo físico - hã - uma parte da pessoa Kaingang, ele começa a existir logo que ocorre a copulação e que o óvulo é fecundado. O homem contribui com o sêmen que é depositado no útero da mulher, local que o abrigará durante o tempo necessário para que se constitua completamente.

O pai deixa a parte dele, que nem os brancos. Nada de diferente. No sêmen dele tem as substâncias que depois a criança vai ter, por isso é que ela tem o nome do pai primeiro. Pois é ele que inicia o desenvolvimento dela, do corpo, né? (GÃN RHE, dezembro 2007).

A mãe o sustenta e o desenvolve através dos alimentos e outros cuidados. Desse modo, pais, filhos e irmãos estão ligados por laços ao longo da vida através da identidade corporal. Em relação a isso, Gãn Rhe comenta:

o que mais puxou o João foi o Kenghĩn: ele tem o corpo igual o do pai, as perninhas tornas e o Ken che tem as bochechas iguais, o rosto redondo. Dá pra saber que eles são tudo filho do João. Os dois mais velhos, o Karinde e Katumber, são altos que nem o pai deles que foi o meu primeiro marido, né? Lá no Paraná (GÃN RHE, janeiro 2008). 
PATRÍCIA CARVALHO ROSA - A noção de pessoa e a construção de corpos Kaingang ...

A mulher deve ficar o maior tempo possível longe do marido durante a gestação. Inclusive não mantendo relações sexuais para que a criança cresça sem ser incomodada. Antigamente, me contam Gãn Rhe, Kengrimu e sua mãe Renrã, que no tempo delas, era comum as mulheres ficarem em suas casas enquanto o marido saia e ficava com algum parente em outra parte da aldeia para manter um distanciamento da esposa gestante. Isso implica na formação de uma criança agitada que ao longo da vida se tornará alguém muito inconstante, de comportamento agressivo. Ao contrário do que se conhece, por exemplo, entre os Suyá (SEEGER, 1980) e grupos do Alto Xingu (VIVEIROS DE CASTRO, 1979), entre os Kaingang quanto maior o número de copulações existirem durante a gravidez, maior será a dificuldade de desenvolvimento da criança. Talvez, por isso a relevância dada ao silêncio no primeiro mês e a tranqüilidade na gestação. Gãn Rhe diz que "o pai já contribuiu com a parte dele, né? Fez a criança com as substâncias dele, agora é com mãe que o feto se desenvolve. Contribuo pra ele desenvolver com as minhas substâncias, né?" (GÃN RHE).

Ela conta que é possível escolher o sexo da criança através de um processo que envolve o conhecimento de ervas e da prática do aconselhamento. Gãn Rhe menciona "já não é mais comum. Sei de poucos casais que fazem isso. Antigamente era assim. Todos faziam. Tinha menos casal brigando e as regras eram mais sérias" (GÃN RHE).

A prática do aconselhamento e da escolha do sexo do bebê deve ser realizada por alguém que tenha conhecimentos específicos sobre as ervas e remédios. No entanto, não é mencionada a necessidade de ser esta pessoa um kujà. Para que o conselheiro ou o kujà possa atuar na escolha do sexo de uma criança é necessário antes de qualquer decisão que os pais estejam em pleno acordo da opção desejada. Nesse sentido, o papel do conselheiro é atuar na mediação do processo de escolha do sexo da criança. Comenta-se entre alguns informantes que o ideal é que seja uma mulher e que essa deva ter uma relação próxima com os genitores. Renrã (mãe de Gãn Rhe) menciona que não é obrigatório que tal conselheira seja uma parenta, mas mantenha com o casal uma relação de afinidade. Essa conselheira, normalmente, é alguém que tem alguma experiência relacionada às práticas de acompanhamento da gravidez e/ou é parteira. 
PATRÍCIA CARVALHO ROSA - A noção de pessoa e a construção de corpos Kaingang ...

O aconselhamento pode ter a duração de alguns dias. 0 procedimento é simples de acordo com os relatos de Gãn Rhe.

Os pais da criança visitam a conselheira em sua casa para consultar com ela, e aí lá conversam por uns dias. Já atendi muitas das minhas primas e também as minhas irmãs mais novas que não tinham muita experiência sobre isso. Aprendi com minha mãe que foi parteira quando era mais nova (GÃN RHE, janeiro 2007).

Uma vez decidido qual sexo terá a criança, a conselheira caso não saiba qual a erva apropriada "como de costume consulta ela mesma o kujà". Quando possível, o faz pessoalmente, ou então através do sonho. Em relação ao segundo modo, Gãn Rhe relata que "ela (a conselheira) pede antes de adormecer para sonhar com o iangré dela" ${ }^{23}$. Dessa maneira o kujà indica o lugar onde estão e quais as ervas necessárias. Ressalta que para obter sucesso o processo de escolha deve seguir algumas regras: "é preciso esperar a chegada da lua certa para colher o chá de acordo com a escolha dos pais. Isso o iangré do kujà diz pro iangré da conselheira no sonho também. Aí quando acorda, já sabe como fazer" (GÃN RHE). Quando a conselheira pode pessoalmente depois da conversa com o casal visitar o kujà, este utiliza a fumaça para ter informações sobre a indicação certa. Com fumaça na boca, o kujà assopra sobre a palma da mão da conselheira e identifica qual a erva e o local onde encontrá-la.

Se desejarem que seja um menino, o chá é feito com Me (o fruto e a folha da jabuticaba) e deve ser colhido durante a lua crescente (kysã téi). Caso a escolha seja uma menina, o chá é preparado com Féi Kusun (uma flor vermelha da qual se usa a raiz) e deve ser colhido durante a lua minguante ou lua cheia (kysã ror). Uma vez colhido o chá, a mãe deve ingerir duas vezes a mistura específica antes que seu próximo ciclo

\footnotetext{
${ }^{23}$ No caso de Gãn Rhe que foi iniciada ainda muito pequena por um kujà (que reside hoje em Nonoai) a pedido de seu avô com quem morou desde que tinha oito meses de idade. Seu avô antes de falecer havia iniciado o processo de formação dela como kujà. Processo ainda não finalizado, faltando apenas que ela viaje ao encontro de seu iniciador em Nonoai. Para que juntos encerrem o processo de aprendizagem quando irá sozinha passar uma noite no mato levando uma comida especial que seu iniciador lhe dirá para oferecer ao seu iangré. Caso esse a coma é sinal de que seu iangré a aceitou e estará pronta a partir de então para atuar como kujà. Gãn Rhe conta detalhadamente o seu processo de aprendizagem, mas pede para que não o mencione ainda, pois é de regra, manter segredo em relação a esse acontecimento. Inclusive para seus parentes e afins. Segundo ela é necessário respeitar o $\tilde{u}$ mỹ tó tũg (segredo) que cerca esse acontecimento.
}

Espaço Ameríndio, Porto Alegre, v. 2, n. 1, p. 15-43, jan./jun. 2008. 
PATRÍCIA CARVALHO ROSA - A noção de pessoa e a construção de corpos Kaingang ...

menstrual ocorra. O ideal, segundo Gãn Rhe, para que o processo de escolha do sexo corresponda à expectativa desejada pelos pais a consulta à conselheira deve ser realizada durante a lua cheia (Kysã ror).

\section{A gestação e as relações de substâncias}

Constatada a gravidez, para que o feto se desenvolva bem é preciso que a mãe esteja durante o primeiro mês de gestação em tranqüilidade. Nesse sentido, o silêncio é um elemento constituinte e importante para a formação do corpo da criança na barriga da mãe. Durante esse período é que ocorre o início da formação da parte física do bebê e momento em que, segundo Gãn Rhe, o feto procura se acomodar dentre do útero da mãe "indo de um lado para o outro buscando um local para ficar". Esse período é também tido como limiar das práticas femininas sobre e com o feto. O ciclo da vida Kaingang e a existência da pessoa são considerados em dois momentos bem definidos. Inicia-se o ciclo da vida, ao nascer uma criança, momento no qual ela recebe os nomes Kaingang e passa a fazer parte do mundo na Terra. Ao receber o seu nome essa criança recebe o status de pessoa Kaingang.

Subjacente a essas informações, há ainda um aspecto que julgo relevante para apreender o processo e o modo êmico de entendimento da pessoa Kaingang. O pai colabora, segundo os relatos das mulheres com quem conversei, com a formação do corpo da criança quando através do sêmen ele compartilha seus atributos com o hã em construção. A partir disso, o contato e as trocas passam a ser efetuados pela mãe, que mantém um vínculo constante e mais próximo com o hã até o momento do nascimento. Desse modo, sugiro ser a mãe o invólucro que sustenta o hã em formação. A participação masculina passa a ser realizada após o parto.

A partir dos dois meses de gestação, a mãe passa a banhar-se uma vez por mês com uma mistura de ervas específicas que operam como eméticos. Tais remédios atuam diretamente no corpo da mãe. Através dela, o corpo em construção incorpora as propriedades das ervas que compõem a mistura. Assim, no segundo mês ela inicia o 
PATRÍCIA CARVALHO ROSA - A noção de pessoa e a construção de corpos Kaingang ...

banho com apenas duas ervas utilizando as suas folhas, a saber, penóide e penva (a primeira Gãn Rhe não conhece o nome em português e a segunda é conhecida como gabirova ${ }^{24}$ ). No terceiro mês, o banho é preparado com as duas ervas utilizadas no primeiro banho, adicionando uma terceira erva. No quarto mês, as ervas usadas mencionadas e mais as folhas de pri $^{25}$ (conhecida em português por samambaia de ponta vermelha). Acrescentando as folhas da guabijú - Karinde ${ }^{26}$ - é preparada a mistura no quinto mês de gestação.

Os banhos seguem até o nono mês de gestação. Sua função é preparar o corpo da gestante para as mudanças que ocorrem durante a gravidez, fortalecendo os músculos da região pélvica e dando elasticidade suficiente para que a barriga acompanhe o crescimento do bebê. Esses banhos atuam também no corpo da criança na barriga da mãe. Ajudam de modo geral, a manter o vínculo entre a mãe, o seu corpo e propriedades com o corpo do bebê.

Nesse sentido, os chás permitem que o corpo da mãe, ao banharse com as ervas e com o remédio, absorva as substâncias contidas na mistura e compartilhe estas com o hã em desenvolvimento, e fortalecendo, portanto, o seu próprio corpo. O preparo do remédio deve ser com água corrente e, preferencialmente, a gestante deve banhar-se também em água corrente. A água (gój) fortalece o corpo do Kaingang. Banhar-se em água corrente é a receita nativa para manter o corpo forte e saudável.

O exemplo revela a crença de que compartilhando as mesmas substâncias corporais, os sujeitos ligados por esse elo serão atingidos de mesmo modo pelos alimentos ou outros conteúdos que designem algum fator que relacione os corpos. Isso se refere diretamente ao conceito de relações de substâncias que Da Matta e Melatti (apud SEEGER, 1980, p. 129), em estudos sobre os Apinayé e os Krahó, respectivamente, consideraram como laços entre parentes próximos não

\footnotetext{
${ }^{24}$ O banho com tais folhas é utilizado para a proteção da família, sendo importante que a mãe, considerada aquela responsável pela casa banhe-se.

${ }^{25}$ Essa folha é um elemento fundamental para compor o banho. Ela afasta os vein kupri (espíritos dos mortos que vagam pelo vento ameaçando os vivos).

${ }^{26} \mathrm{O}$ preparar do chá é feito deixando as folhas de molho em água por dois dias antes de usar. Atua na pele. Recomendado para gestantes para que o corpo suporte o peso ganho conforme passam os meses e o tamanho do bebê aumenta.
} 
PATRÍCIA CARVALHO ROSA - A noção de pessoa e a construção de corpos Kaingang ...

ligados necessariamente por consangüinidade e sim por afinidade ${ }^{27}$. Tais relações constituem trocas permanentes de substâncias corporais que formam o corpo do sujeito desde sua fecundação, prolongando-se pelo restante da vida adulta.

\section{As restrições alimentares}

Durante o período de gestação, os cuidados com a alimentação são aspectos importantes de serem apresentados. Embora sejam poucas as prescrições alimentares conhecidas e utilizadas por minhas informantes, essas mulheres falam desses cuidados com muita ênfase, explicitando nas conversas a importância de não cometer erros em relação à ingestão de certos alimentos. A moela da galinha, por exemplo, é proibida de ser ingerida durante o período de gestação. Essa parte do animal é considerada um alimento proibido, pois sugere especialmente nesse momento "o fechamento do útero da mulher, ela fica fechada; essa parte da galinha é uma bolsinha bem fechadinha, difícil de cortar" (GÃN RHE). Desse modo, a ingestão desse alimento implica dificuldades na hora do parto, impossibilitando que o hã consiga alcançar a parte externa, ficando preso dentro da barriga da mãe.

Por outro lado, o consumo de ovos é indicado para a gestante por estar relacionado à fertilidade e ao nascimento. $O$ sangue de qualquer animal é considerado um tabu para os Kaingang de modo geral. As mulheres afirmam que ingerir sangue de algum animal a pessoa fica doente $^{28}$. Gãn Rhe conta que:

não se pode misturar o sangue dos humanos com os dos animais, se a pessoa faz isso, ele pode perder o espírito dela e virar animal, daí. O sangue daquele animal entra no sangue dela e torna ela igual a ele, nem o kujà e seu iangré consegue trazer de volta o kuprig dela (GÃN RHE, janeiro 2008).

\footnotetext{
${ }^{27}$ Ver texto de Viveiros de Castro (2002) sobre a distinção entre afinidade, consangüinidade e nexos de parentesco. E Silva (2001) para conhecer exemplos de trocas de substâncias entre afins.

${ }^{28}$ Adoecer é, nesse sentido, para Jagtyg, correr o risco do sujeito que ingerir o sangue, por metamorfose, tornar-se o animal morto.
} 
PATRÍCIA CARVALHO ROSA - A noção de pessoa e a construção de corpos Kaingang ...

\title{
O nascimento e o período pós-parto
}

O nascimento da criança Kaingang marca o início de sua vida e condição humana. Isso ocorre, a partir desse momento, na medida em que ela está apta a receber um nome e desse modo ter agregado ao hã (já formado sua parte inicial pela mãe e seus cuidados específicos mencionados anteriormente) o seu kuprig. A partir desse período, portanto, é considerada a existência da pessoa Kaingang. Relacionado ao parto, Véingé, antiga parteira, de 52 anos, conta que:

\begin{abstract}
Para parir bem, a mulher toma chá de guaxuma, tem que ser a de sete pontas. O chá dessa folha ajuda a dilatar e aí fica mais fácil ter o filho. As índias não precisam com esse chá ficar deitadas. Ganhamos de cócoras por que o chá dá força nas pernas e na barriga (VÉINGÉ, janeiro 2007).
\end{abstract}

Alguns cuidados são recomendados para os primeiros dias após o nascimento da criança. Entre eles, é considerado necessário que a criança seja banhada com água pura/limpa, de preferência fria, para que o corpo seja fortalecido contra as doenças e torne-se protegido contra os espíritos dos mortos, pois o seu corpo ainda é muito frági ${ }^{29}$. O vento é outro elemento que requer atenção. É importante que o recémnascido não pegue vento. Por ter o corpo ainda muito frágil, e nele sempre haver a possibilidade dos espíritos do kuprig korég viajarem através dele e o kuprig da criança pode ser roubado. A exposição ao vento torna-se perigosa somente após o recebimento do nome. Do contrário, não há regras especificas quanto a isso.

Segundo Gãn Rhe, o principal cuidado que a mãe deve ter logo que a criança nasce é guardar o umbigo. Esse deve ser enterrado na terra onde ela nasceu, pois quando morrer, o seu corpo volta pra junto da terra. Isso apenas ressalta que o ciclo de vida Kaingang é marcado pela intensa relação com a terra. Ao nascer e ao morrer a parte do corpo

\footnotetext{
${ }^{29}$ A água, segundo as narrativas mitológicas Kaingang, possui uma característica dual. No plano da terra, a água que brota do chão é considerada terapêutica, especialmente as frias, encontradas nos riachos e águas correntes próximas de cachoeiras e rios. Essas, segundo os mais antigos, têm propriedades de cura e fortalecem o corpo do sujeito que se banha nelas. Seu Kaxú, de aproximadamente 80 anos, relata que os velhos alcançam idades avançadas devido aos banhos diários em águas frias antes mesmo de o sol raiar, momento em que os donos das águas (goj tán) ainda não despertaram. As águas noturnas são associadas à lua e parecem não ter uma relação direta com as práticas de construção de corpos.
}

Espaço Ameríndio, Porto Alegre, v. 2, n. 1, p. 15-43, jan./jun. 2008. 
PATRÍCIA CARVALHO ROSA - A noção de pessoa e a construção de corpos Kaingang ...

é posto na terra, enquanto o espírito provém e retorna a sua aldeia no numbê.

É recomendável que a mãe coma bastante caldo de canjica misturado com cinzas. Esse alimento contribui para que a mãe produza leite, uma vez que cinza tem propriedades que fortalecem o corpo feminino. A produção de bolos como a amí ou pixé feitos na brasa são alimentos muito apreciados pelas mulheres nesse período.

\section{Complementaridade entre gêneros e metades e a construção de corpos Kaingang}

No que refere-se ao período posterior ao nascimento da criança, o que as conversas com as Kaingang sugerem é que há um compartilhamento das práticas que formam tanto o corpo como o caráter dos filhos. A saber, alguns exemplos que Gãn Rhe revela ao longo de algumas conversas, e uma em particular com a presença de seu marido, Mín. Ela me conta que para manter os cabelos fortes e bonitos durante a gestação é recomendável usar sobre eles, também a partir do segundo mês de gravidez, com a freqüência de uma vez por semana, Kaboãtã (não conhecem a denominação em português). Outro exemplo citado pelo casal é a mistura da gordura do estômago de galinha caipira com chá de cipó milone. Esse óleo atua no corpo da mãe e da criança e deve ser aplicado nas juntas ósseas e musculares, para fortalecê-las. E um terceiro exemplo, é o preparo com a gordura do lagarto ou tatu peludo que passado também sobre a cabeça auxilia na memória e segundo eles, atribui "juízo aos jovens". Mín menciona que lavar as crianças com a água que sobra da primeira cozida de pinhão do ano atua no fortalecimento das pernas, sendo que esse banho deve ser apenas dado da cintura para baixo e simbolicamente significa que os meninos poderão ser bons caçadores e as meninas boas coletoras de sementes. Por fim, há alguns alimentos considerados relevantes na formação e construção de corpos Kaingang e que são de consumo fundamental no cotidiano: o primeiro é o mel (g̃my) é um alimento considerado masculino. E o segundo é o leite (gjẽnu) considerado um alimento feminino, com propriedades tranqüilizantes e que simboliza o 
elo entre mãe e filhos ${ }^{30}$. Ambos simbolizam a complementaridade entre os papéis de gênero nesse processo de construção de corpos sociais Kaingang. A coleta do mel, antigamente, estava relacionada a uma atividade masculina; enquanto amamentar uma atividade exclusivamente feminina. Nesse sentido, as mulheres Kaingang dizem que ao consumir alimentos que os pais $e$ as mães preparam individualmente, como os exemplos citados, ambas contribuem para que a criança apreenda as propriedades das duas partes através de duas substâncias assimétricas, mas complementares.

Esses últimos exemplos apresentados referem-se ao período pósparto e podem ser utilizados sem restrições ao longo da vida da mulher e de seus filhos. O que busco apontar é o modo como o compartilhamento das informações e conhecimentos sobre o corpo é distinto entre homens e mulheres. As práticas relacionadas ao corpo no período de gestação, nesse caso, a utilização de eméticos e outras misturas são de domínio do universo feminino. Algumas práticas são também do conhecimento dos homens, mas na sua maioria, cabe às mulheres os cuidados com o corpo nesse período.

Nesse sentido, os exemplos citados permitem ainda pensar as questões referentes aos papéis de gênero na constituição da pessoa Kaingang e os aspectos sobre corporalidade. Em outras palavras, as atividades que são compartilhadas requerem certas práticas que cabem aos homens, como a caça, no caso do tatu peludo e do lagarto. Às mulheres cabe a responsabilidade do preparo dessa carne trazida para a casa pelo marido, retirando os elementos que formam a mistura utilizada nos cuidados corporais. Por último, poder-se-ia refletir ainda acerca da complementaridade presente nas relações de sociabilidade e práticas sociais de construção do corpo e da pessoa Kaingang na medida em que o sujeito é constituído pelo compartilhamento dos atributos do pai e da mãe. Sobre isso, Mín comenta:

Somos todos um conjunto. Quando algum não está bem, não funciona, o resto pára. É mais ou menos assim com o nosso corpo. Se alguma coisa tá meio errada, se um chá foi feito errado ou se o corpo tá enfraquecido, o espírito vai embora. Por isso é que os

\footnotetext{
${ }^{30} \mathrm{O}$ leite segundo Gãn Rhe é o que faz as crianças e adultos ficarem calmos. Independente da idade, sempre que seus filhos estão tristes ou muito nervosos e agitados ela lhes oferece leito do peito.
} 
homens e as mulheres fazem coisas diferentes. Daí eles conseguem contribuir um pouco cada um e as coisas funcionam. Os filhos crescem bem e tornam-se pessoas boas (MÍN, dezembro de 2007).

\section{Considerações finais}

Este artigo, de modo geral, buscou apresentar informações que contribuíssem para seguir refletindo acerca dos processos de sociabilidade Kaingang, especialmente, aqueles que envolvem as temáticas da noção de pessoa e construção de corpos. Nesse sentido, o foco da análise nos papéis de gêneros que tangem tais temáticas possibilitou compreender os modos distintos e complementares, a partir dos quais, homens e mulheres constituem uma trama de relações sociais fundamentadas sob a lógica dual do cotidiano Jê. Os corpos, atualmente, construídos entre os Kaingang pesquisados e seus modos particulares de entendimento demonstram ainda a relevância de se considerar as mudanças relacionadas ao território e suas constantes mobilidades. $O$ fato de estarem no espaço urbano não reflete a perda de seus referenciais culturais e, tampouco, de suas práticas cotidianas que julgam eficazes para a formação da pessoa Kaingang e seu corpo respectivo.

\section{Referências bibliográficas}

ALMEIDA, Ledson Kurtz de. Análise antropológica das Igrejas Cristãs entre os Kaingang baseada na etnografia, na cosmologia e dualismo. 2004. $278 \mathrm{f}$. Tese (Doutorado em Antropologia Social) - PPGAS, UFSC, [2004].

CRÉPEAU, Robert R. Mito e ritual entre os Índios Kaingang do Brasil meridional. Horizontes Antropológicos, Porto Alegre, v. 3, n. 6, p. 173-186, 1997.

Os Kamé vão sempre primeiro: dualismo social e reciprocidade entre os Kaingang. In: Anuário Antropológico 2005. Rio de Janeiro: Tempo Brasileiro, 2006. p. 9-33. 
A prática do xamanismo entre os kaingang do Brasil meridional: uma breve comparação com o xamanismo Bororo. Horizontes Antropológicos, Porto Alegre, v. 8, n. 18, p. 113-129, 2002.

FERNANDES, Ricardo Cid. Política e Parentesco entre os kaingang: uma análise etnológica. 2003. 288 f. Tese (Doutorado em Antropologia Social) - PPGAS, USP, [2003].

FERNANDES, Ricardo Cid; ALMEIDA, Ledson Kurtz; SACCHI, Ângela C. Papéis de Gênero Kaingang: organização ritual e doméstica. In: REUNION DE ANTROPOLOGIA DEL MERCOSUR, III, 1999. Posadas/Argentina. Paper.

FREITAS, Ana Elisa de. Mrur Jykre: a cultura do cipó - territorialidades Kaingang na bacia do Guaíba. 2005. Tese (Doutorado em Antropologia Social) - PPGAS, UFRGS, [2005].

NIMUENDAJU, Curt. "Notas sobre a organização religiosa e social dos Índios Kaingang. In: __ (Org.). Etnografia e indigenismo: sobre os Kaingang, os OfaiéXavante e os índios do Pará. Campinas: Editora da UNICAMP, 1993. p. 57-69.

ROSA, Rogério R. Os kujà são diferentes: um estudo etnológico do complexo xamânico dos Kaingang da terra indígena Votouro. 2005. 408 f. Tese (Doutorado em Antropologia Social) - PPGAS, UFRGS, [2005].

SEEGER, Anthony; DA MATTA, Roberto; VIVEIROS DE CASTRO, Eduardo B. A construção da pessoa nas sociedades indígenas brasileiras. In: OLIVEIRA, João P. (Org.). Sociedades indígenas e indigenismo no Brasil. Rio de Janeiro: Marco Zero, 1987. p. 11-29.

SEEGER, Anthony. Corporação e corporalidade: ideologia de concepção e descendência. In: ___ Os Índios e Nós: estudos sobre sociedades tribais brasileiras. Rio de Janeiro: Campus, 1980. p. 127-131.

SILVA, Sergio Baptista da. Etnoarqueologia dos grafismos 'Kaingang': um modelo para a compreensão das sociedades Proto-Jê meridionais. 2001. 367 f. Tese (Doutorado em Antropologia Social) - PPGAS, USP, [2001].

. Nomes e performances: fabricando corpos Kaingang. In: SILVEIRA, Elaine da. Etnoconhecimento e saúde dos povos indígenas do RS. Canoas: Ed. da ULBRA, 2005. p. 89-100.

TURNER, Terence. Social body and embodied subject: Bodiliness, subjectivity, and sociality and the Kayapó. Cultural Anthropology, New York, v. 10, n. 3, p. 54-61, 1995.

VEIGA, Juracilda. Organização Social e Cosmovisão Kaingang: uma introdução ao parentesco, casamento e nominação em uma sociedade Jê Meridional. 1994. 220 f. Dissertação (Mestrado em Antropologia Social) - IFCH, UNICAMP, [1994]. 
PATRÍCIA CARVALHO ROSA - A noção de pessoa e a construção de corpos Kaingang ...

VIVEIROS DE CASTRO, Eduardo B. A fabricação do corpo na sociedade xinguana. In: Boletim do Museu Nacional (Antropologia), Rio de Janeiro, n. 32, p. 40-49, mai. 1979 ,

A inconstância da alma selvagem - e outros ensaios de antropologia. São Paulo: Cosac Naify, 2002. 